IOSR Journal of Pharmacy

ISSN: 2250-3013, www.iosrphr.org

\title{
Kinetic-Spectrophotometric Method for Diclofenac Quantification
}

\author{
Celina M. Monzón, María del C. Sarno* and Mario R. Delfino (h) \\ School of Exact and Natural Sciences - Northeastern National University (UNNE) \\ Instrumental Analysis Laboratory- Av. Libertad 5640- Corrientes- Argentina
}

\begin{abstract}
This paper introduces a kinetic-spectrophotometric method for diclofenac quantification and its application to pharmaceutical preparations. The redox reaction rate between diclofenac and $\mathrm{KMnO}_{4}$ in a strong acidic environment is determined. Plotting initial slope vs. concentration a good linearity has been found. Linear range of the essay was 5-20 ppm. The effect of temperature on the reaction rate has been studied and Ea was $21.48 \mathrm{~kJ} / \mathrm{mol}$. The proposed method was found to be highly precise, having a relative standard deviation, $C V \%=1.3 \%$ for repeatability $(n=10)$. Recovery of analyte in placebo $98.7-108.15 \%$, values that fall within the requirements set by USP and ANMAT (National Drug, Food and Medical Technology Administration of Argentina). This spectrophotometric method was compared with HPLC. Statistical data show no significant difference between them. The proposed method was found to be simple, rapid, specific, allowing the determination without preliminary extraction procedures.
\end{abstract}

Keywords-Diclofenac, kinetics, quantification, spectrophotometry, tablets.

\section{INTRODUCTION}

Diclofenac sodium 2-[2-[(2,6-dichlorophenyl)amino]phenyl]acetate (Fig.1) is a Non-Steroidal AntiInflammatory Drug (NSAID) used to reduce inflammation, and as an analgesic reducing pain, in medical conditions such as osteoarthritis, rheumatoid arthritis and ankylosing spondylitis [1].<smiles>O=C([O-])Cc1ccccc1Nc1c(Cl)cccc1Cl</smiles>

Figure 1: Diclofenac sodium chemical structure

The Medicinal Plant of Corrientes (PLAMECOR) under The Ministry of Public Health produces tablets of $50 \mathrm{mg}$ of diclofenac for distribution in primary care centers across the province.

Several methods for diclofenac quantification in pure form and in tablets have been used. USP (United States Pharmacopoeia) recommends its determination by liquid chromatography methods [2, 3, 4]. The main research interests regarding diclofenac determination have focused on electrochemical techniques such as: cyclic voltammetry [5]; potentiometric sensor [6]; capillary electrophoresis [7]. Other papers focus on diclofenac quantification in vivo using HPLC-MS [8,9]. A great deal of research papers are focused on official method validation concerning drug release from dosage forms [10, 11, 12, 13, 14].

However, spectrophotometric UV-visible techniques are preferred given its high selectivity and simplicity. Diclofenac-Fe (III) and Diclofenac-Cu (II) complexes have been studied [15, 16]. The same authors developed a technique based on diclofenac oxidation by Fe (III) in the presence of o-phenanthroline [17].

ANMAT (National Drug, Food and Medical Technology Administration of Argentina), has not yet established analytical methods for diclofenac tablets quality control.

This paper introduces a simple, versatile, cost-efficient and fast quantitative diclofenac determination by a kinetic-spectrophotometric method and its application to pharmaceutical preparations.

The kinetic differential method involves measuring reagent concentration from de initial slope of the absorbance vs. time curve. This parameter is linearly related with initial analyte concentration $[18,19,20]$.

In this method the redox reaction rate between diclofenac and $\mathrm{KMnO}_{4}$ in a strong acidic environment is determined. A pseudo zero order reaction is verified with respect to diclofenac concentration. The effect of temperature on the reaction rate has been studied and activation energy was determined. 
Implementation of a new analytical method requires a validation procedure, therefore basic parameters were determined: precision, accuracy, specificity, linearity and linear range [21, 22]. This method was compared with HPLC.

\section{MATERIALS AND METHODS}

\subsection{Samples}

Diclofenac in pure form lot 080301-5 (powder), origin China, (99.99 \% purity, determined by HPLC method) and diclofenac $50 \mathrm{mg}$ tablets lot $\mathrm{N}^{\circ}$ 103/12 from PLAMECOR were used.

Placebo used in specificity and accuracy determinations, was provided by PLAMECOR and its composition is the same present in the tablet: magnesium stearate $1 \%$, talc $2 \%$, sodium starch glycolate $3.5 \%$, polyvinylpyrrolidone (PVP) $1.2 \%$ and $73.2 \%$ green precompact powder.

\subsection{Reagents}

$\mathrm{KMnO}_{4}$ AR Cicarelli (Argentina)

$\mathrm{H}_{2} \mathrm{SO}_{4} 98 \%$ AR Cicarelli (Argentina)

\subsection{Equipment}

Boeco S-26 UV-visible spectrophotometer.

Jenway Heated Cell Block Controller. Model: 633004. Temperature range: Ambient $+2^{\circ} \mathrm{C}$ to $60^{\circ} \mathrm{C}$ Accuracy: $\pm 0.5^{\circ} \mathrm{C}$

HPLC: Agilent 1120 compact LC, with UV detection.

\subsection{Techniques}

Working solutions for spectrophotometric method

$\mathrm{H}_{2} \mathrm{SO}_{4} 6 \mathrm{~N}$.

$\mathrm{KMnO}_{4} 7.42 \times 10^{-4} \mathrm{M}$ in $\mathrm{H}_{2} \mathrm{SO}_{4} 1 \mathrm{~N}$.

Active Ingredient working solutions of $600 \mathrm{ppm}, 716$ and $160 \mathrm{ppm}$ were prepared by weighing the necessary amount of the compound, leading to volume with distilled water and stirred magnetically for $10 \mathrm{~min}$. Then centrifuged at $800 \mathrm{rpm}$ for $5 \mathrm{~min}$.

Diclofenac tablets working solutions of $600 \mathrm{ppm}$ and $163 \mathrm{ppm}$ were prepared from a pool of 10 tablets, following the same procedure as the active ingredient.

\subsection{Spectrophotometric Procedure}

The spectrophotometer was set at $524 \mathrm{~nm}$ and the thermostatic cell was set at $30^{\circ} \mathrm{C}$.

Diclofenac pure form analysis: $2 \mathrm{~mL}$ of $\mathrm{KMnO}_{4} 7.42 \times 10^{-4} \mathrm{M}$ and $1 \mathrm{~mL}$ of $\mathrm{H}_{2} \mathrm{SO}_{4} 6 \mathrm{~N}$ were added to a thermostated cuvette and incubated inside the spectrophotometer during $10 \mathrm{~min}$. An aliquot of $25 \mu \mathrm{L}$ of diclofenac pure form $600 \mathrm{ppm}$ solution was added and homogenized with micropipette. Since it is a batch system, measurements at time zero were made at the closing of the spectrophotometer lid. Absorbance was recorded every $5 \mathrm{~s}$ during a $30 \mathrm{~s}$ period. The procedure was repeated for additions of 50,75 and $100 \mu \mathrm{L}$ of diclofenac pure form $600 \mathrm{ppm}$ solution. The additions were made for initial concentrations of diclofenac in the cell of 5.95, 11.80, 17.56 and $23.22 \mathrm{ppm}$. Absorbance vs. time was plotted and slope was determined using the method of initial rates. A calibration curve of initial slope $(\Delta \mathrm{A} / \Delta \mathrm{t})$ vs. $\mathrm{C}$ was constructed.

Diclofenac tablets analysis: $2 \mathrm{~mL}$ of $\mathrm{KMnO}_{4} 7.42 \times 10^{-4} \mathrm{M}$ and $1 \mathrm{~mL}$ of $\mathrm{H}_{2} \mathrm{SO}_{4} 6 \mathrm{~N}$ were added to a thermostated cuvette and incubated inside the spectrophotometer during 10min. An aliquot of $50 \mu \mathrm{L}$ of diclofenac tablet $600 \mathrm{ppm}$ solution was added and homogenized with micropipette. Again measurements at time zero were made at the closing of the spectrophotometer lid Absorbance was recorded every 5s during a 30s period. Absorbance vs. time was plotted and initial slope was determined. Diclofenac concentration was calculated using the calibration curve constructed with diclofenac pure form.

\subsection{Activation Energy}

The method was performed at various temperatures $\left(30,45,50,55\right.$ and $\left.60{ }^{\circ} \mathrm{C}\right)$. An Arrhenius plot was used to analyze the effect of temperature on the rate of the chemical reaction. Activation Energy (Ea) was calculated using the Arrhenius equation [23].

\subsection{Method Validation}

For linearity study a calibration curve was constructed with diclofenac pure form in a concentration range between 5 and 23 ppm.

Specificity was assessed by spectrophotometric readings of placebo prepared with excipients in the same proportion as found in $50 \mathrm{mg}$ diclofenac tablets.

Precision was analyzed as repeatability. A number of 10 aliquots of a homogeneous sample $(50 \mu \mathrm{L}$ of diclofenac tablet $600 \mathrm{ppm}$ solution) were analyzed on the same day, by the same operator, using the same instrument.

Accuracy was based on the recovery of known amounts of analyte in placebo. Spiked samples with different levels of diclofenac $(30 ; 60$; and $90 \mu \mathrm{L}$ diclofenac pure form $716 \mathrm{ppm}$ solution) were prepared. The analysis was done in triplicate. 


\subsection{HPLC -UV analysis}

For diclofenac measurement mobile phase consisting of a filtered and degassed mixture of methanol and phosphate buffer $\mathrm{pH} 2.5$ (70:30) was used. Diluent was a methanol and water mixture (70:30). Column: RP$18 \mathrm{C}, 125 \times 4.5 \mathrm{~mm}$. Flow rate was $1 \mathrm{~mL} / \mathrm{min}$. Detection wavelength was set at $276 \mathrm{~nm}$. Injection volume was 20 $\mu \mathrm{L}$. Diclofenac pure form $160 \mathrm{ppm}$ solution and Diclofenac tablets solution $163 \mathrm{ppm}$ were used. Identity was verified with diclofenac retention time $(9.3 \mathrm{~min})$. Peak areas were determined. Conversion of peak area (A) to concentration levels $(\mathrm{C})$ was based on equation 1

$\mathrm{C}_{\text {sample }}=\mathrm{C}_{\text {diclofenac pure form }} \cdot \mathrm{A}_{\text {pure form }} / \mathrm{A}_{\text {sample }}$

\section{Equation 1}

\section{RESULTS AND DISCUSSION}

Absorbance vs. time was plotted (Fig. 2) and data obtained were processed using the method of initial rates. The slope of each curve at zero time was found to be proportional to diclofenac initial concentration

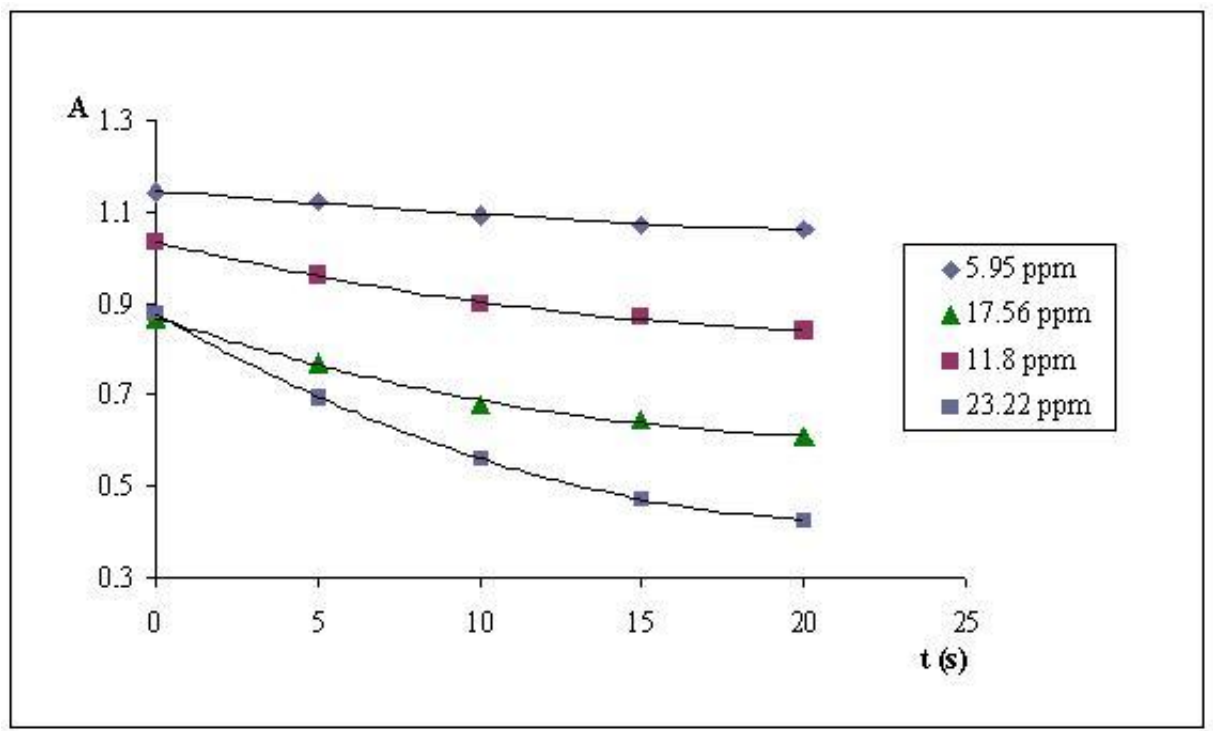

Figure 2: Absorbance vs. time for different diclofenac concentration levels

Calibration Curve: plotting initial slope $(\Delta \mathrm{A} / \Delta \mathrm{t}) \mathrm{i}$ vs. Diclofenac initial concentration $(\mathrm{Ci})$ a good linearity has been found from the regression analysis $[y=0.0012 x-0.0019]$ with $r^{2}=0.9925$ with a $95 \%$ confidence level. Linear range of the essay was 5-23 ppm (Fig 3).

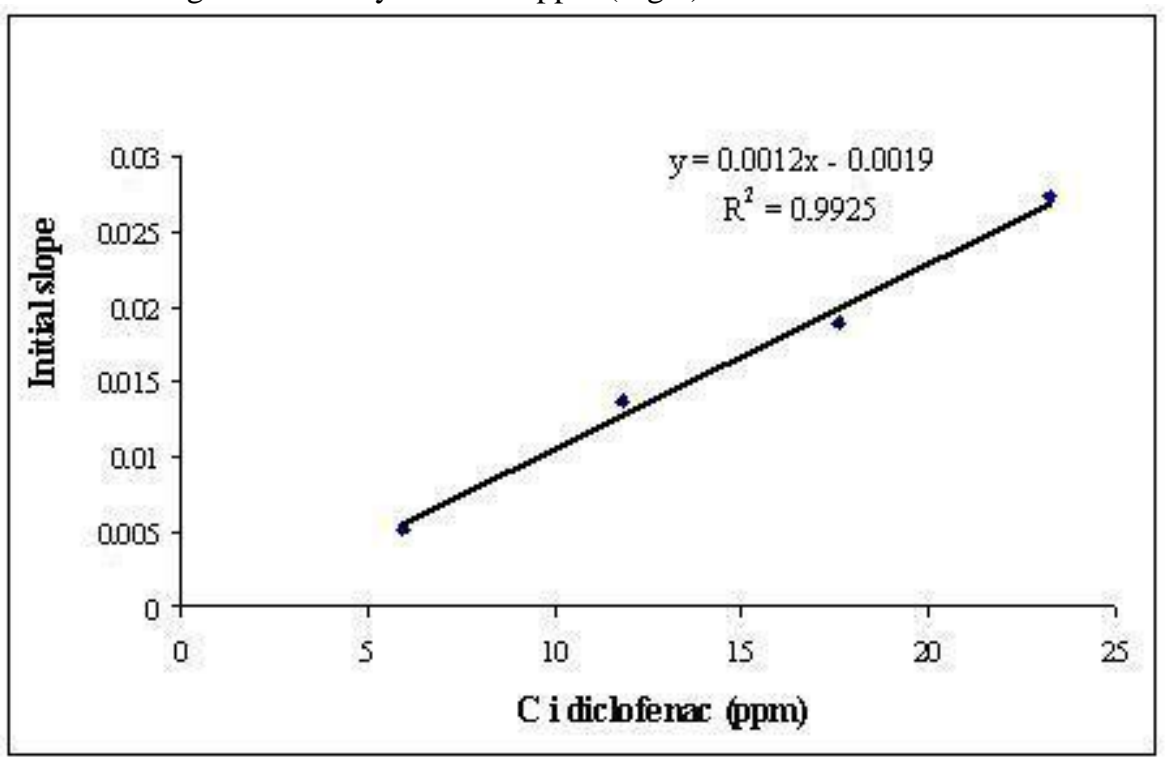

Figure 3: Differential kinetic method calibration curve, $(\Delta \mathrm{A} / \Delta \mathrm{t}) \mathrm{i}$ vs. Ci of diclofenac $(\mathrm{ppm})$ 
Spectrophotometric analysis of placebo demonstrates the chemical inertia of diclofenac tablets excipients to $\mathrm{KMnO}_{4}$ oxidation, and therefore the specificity of the method.

The proposed method was found to be highly precise, having a Relative Standard Deviation for repeatability $(\mathrm{n}=10)$ of $1.3 \%$, below the maximum amount accepted by the pharmacopoeias for pharmaceutical preparations $(\mathrm{CV} \% \leq 2 \%)$.

Accuracy: recovery of analyte in placebo $98.7-108.15 \%$, values that fall within the requirements set by USP and ANMAT. (Table 1)

Table 1: Accuracy (recovery of analyte in placebo)

\begin{tabular}{|cccc|}
\hline $\mathbf{V}_{\text {dlelo } 716 \mathrm{ppm}}(\mathbf{m L})$ & $\mathbf{C}$ (ppm) & recup mass & recup \% \\
\hline \multirow{3}{*}{30} & 7.67 & 193.58 & 108.15 \\
\cline { 2 - 4 } & 7.58 & 191.48 & 106.97 \\
\cline { 2 - 4 } & 7.33 & 185.17 & 103.45 \\
\hline \multirow{3}{*}{60} & 14.92 & 190.19 & 106.25 \\
\cline { 2 - 4 } & 14.25 & 181.69 & 101.50 \\
\cline { 2 - 4 } & 14.75 & 188.06 & 105.06 \\
\hline \multirow{3}{*}{90} & 20.67 & 177.39 & 99.10 \\
\cline { 2 - 4 } & 21.00 & 180.25 & 100.70 \\
\cline { 2 - 4 } & 20.58 & 176.67 & 98.70 \\
\hline
\end{tabular}

The effect of temperature on the rate of the chemical reaction was analyzed with an Arrhenius plot (Fig 4).

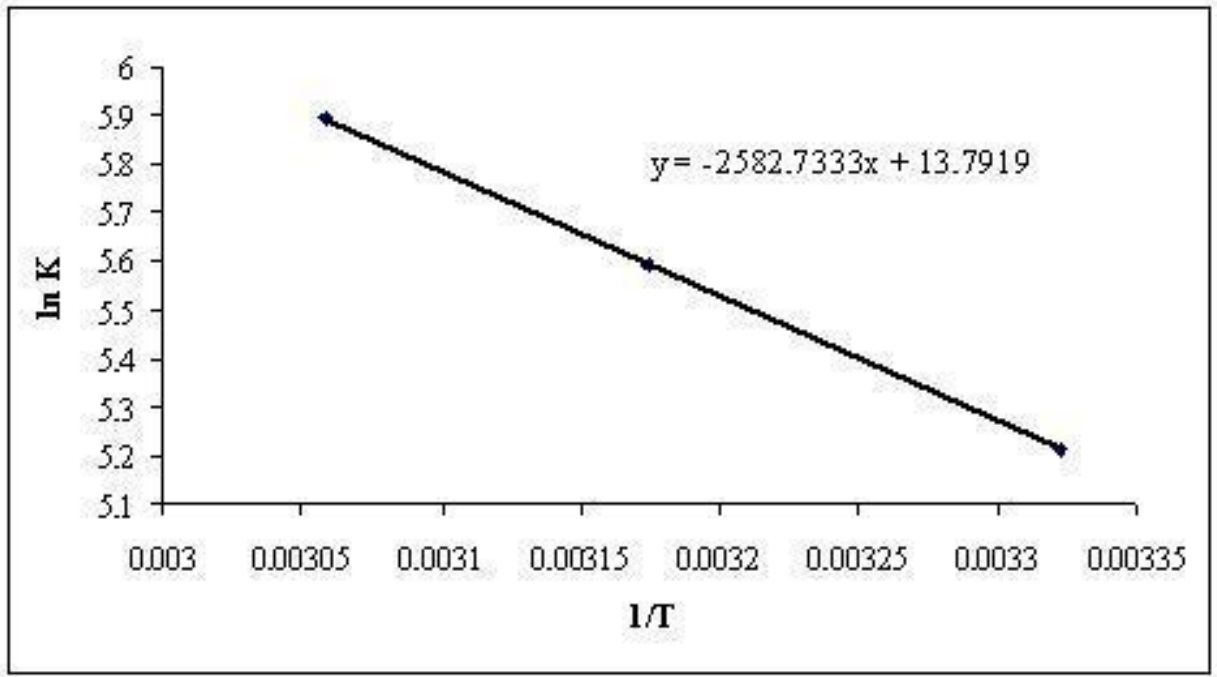

Figure 4: Arrhenius plot

Activation energy, Ea, calculated with Arrhenius equation was $21.48 \mathrm{~kJ} / \mathrm{mol}$.

This spectrophotometric method was compared with HPLC. Statistical data obtained by using Student's t-test and F-tests show no significant difference between the methods. A confidence level of $95 \%$ was considered. Results are shown in Table 2.

Table 2: Statistical comparison of the kinetic method with the reference method

\begin{tabular}{|l|l|l|}
\hline Parameter & Kinetic- Spectrophotometric Method & HPLC-UV Method \\
\hline $\mathbf{X m} \pm$ SD & $50.072 \pm 2.03$ & $48.578 \pm 1.21$ \\
\hline RSD\% & 2.508 & 4.053 \\
\hline $\mathbf{S}^{\mathbf{2}}$ & 4.119 & 1.484 \\
\hline F test & $2.7744(3.1788)$ & \\
\hline t test & $-1.9955(2.1009)$ & \\
\hline
\end{tabular}

(Values in parentheses correspond to those tabulated for $\mathrm{p}=0.05$ ). 


\section{CONCLUSIONS}

The kinetic spectrophotometric UV-visible technique with $\mathrm{KMnO}_{4}$ in acidic media has been confirmed to be useful for the quality control of diclofenac $50 \mathrm{mg}$ tablets, without interference from common excipients. This method was found to be simple, rapid and specific, allowing the determination without preliminary extraction procedures.

\section{ACKNOWLEDGMENTS}

This work was supported by a grant from the General Secretary of Science and Technology of the Northeastern National University (UNNE) and the National Council of Scientific and Technical Research (CONICET) of Argentina.

\section{REFERENCES}

[1]. Lorenzo, P.; Moreno, A.; Leza, J. C.; Lizasoain, I.; Moro, M. A, Farmacología Básica y Clínica (17 ed, Spain: Médica Panamericana, 2005)

[2]. United States Pharmacopeia XXIV, National Formulary XX US Pharmacopeial Convention, (Rockville, Maryland: 2002)

[3]. C.Arcelloni, R.Lanzi, S.Pedercini, G.Molteni, I.Fermo, A.Pontirolic, High-performance liquid chromatographic determination of diclofenac in human plasma after solid-phase extraction, J Chromatogr B. 763(1), 2001, 195200.

[4]. O.Kuhlmann, G.Stoldt, H.G Struck, G.J Krauss, Simultaneous determination of diclofenac and oxybuprocaine in human aqueous humor with HPLC and electrochemical detection, J Pharmaceut Biomed. 17(8), 1998, 1351-1356.

[5]. M.C. Blanco-Lopez, L.Fernandez-Llano, M.J Lobo-Castanon et al., Potentiometric immunosensor using artificial antibody based on molecularly imprinted polymers, Anal Lett. 37(5), 2004, 915-927.

[6]. S. Mojtaba, J. Fíame, E. Sohrab, Preparation of a diclofenac potentiometric sensor and its application to pharmaceutical analysis and to drug recovery from biological fluids, J Pharmaceut Biomed 37(5), 2005, 943-947.

[7]. A.R Solangi, S.Q. Memon, A. Mallah, M.Y Khuhawar, M.I. Bhanger, Development and implication of a capillary electrophoresis methodology for ciprofloxacin, paracetamol and diclofenac sodium in pharmaceutical formulations and simultaneously in human urine samples, Biomed Chromatogr. 23(9), 2009, 1007-1013.

[8]. B.X Mayer, K. Namiranian, P. Dehghanyar, R. Stroh, H. Mascher, M. Müller, Comparison of UV and tandem mass spectrometric detection for the high-performance liquid chromatographic determination of diclofenac in microdialysis samples, J Pharmaceut Biomed. Vol 33(4), 2003, 745-754.

[9]. S. Ma, M. M. Zhu, Recent advances in applications of liquid chromatography-tandem mass spectrometry to the analysis of reactive drug metabolites, Chem-Biol Interact. Vol 179(1), 2009, 25-37.

[10]. V.Sánchez, P.Carreño, M.Castelletto, Liberación y permeación de diclofenaco sódico desde matrices hidrofílicas. Acta Farm. Bonaerense. 20(2), 2001, 101- 104.

[11]. S. Rezende Schaffazick, A. Raffin Pohlmann, L. De Lucca Freitas, S. Stanisçuaski Guterres, Caracterização e estudo de estabilidade de suspensões de nanocápsulas e de nanoesferas poliméricas contendo diclofenaco, Acta Farm. Bonaerense. 21(2), 2002, 99-106.

[12]. M. Baccarin, R. Evangelista, R. Lucinda-Silva, Ethylcelullose microspheres containing sodium diclofenac: development and characterization, Acta Farm. Bonaerense. 25(2), 2006, 401- 404.

[13]. L. Dos Santos, S. Guterres, A. Bergold, Caracterização e qualificação de diclofenaco de sódio como padrão secundário, Lat. Am. J. Pharm. 26(3), 2007, 355-361.

[14]. M.Olivera, D. Allemandi, R. Manzo, Equivalencia farmacéutica en comprimidos recubiertos de diclofenac sódico, Acta Farm. Bonaerense. 22(2), 2003, 143-146.

[15]. S. Agatonović-Kuŝtrin, L. Živanović, M. Zečević, D. Radulović, Spectrophotometric study of diclofenac-Fe(III) complex, J Pharmaceut Biomed. 16(1), 1997, 147-153.

[16]. R. De Souza, M. Tubino, Spectrophotometric determination of diclofenac in pharmaceutical preparations, J. Braz. Chem. Soc. 16(5). 2005.

[17]. C. Monzón, M.C Sarno, M. Delfino, Diclofenac quantification: analytical attributes of a spectrophotometric method, Lat. Am. J. Pharm. 30(5,)2011, 1001-1004.

[18]. K. Rubinson, J. Rubinson, Contemporary Instrumental Analysis. (Madrid: Prentice Hall, 2001)

[19]. Avery, H. E. Cinética Química Básica y mecanismos de reacción. (Spain: Ed Reverté, 2002)

[20]. Levenspiel, Octave. Ingeniería de las reacciones químicas. (Spain: Ed Reverté, 2001)

[21]. J.C. Miller, J.N. Miller, Estadística y Quimiometría para Química Analítica, (Madrid: Pearson-Prentice Hall, 2000)

[22]. L. Aguirre Ortega, M. Martín Pomar, Validación de Métodos Analíticos (España: Asociación Española de Farmacéuticos de la Industria, 2001).

[23]. P. Atkins, J. De Paula, Physical Chemistry (Ninth Edition, Great Britain: W.H. Freeman, 2009) 